\title{
Molecular mechanisms of glucocorticoid action: what is important?
}

\author{
Robert Newton
}

\section{Biological effects of glucocorticoids}

Inflammatory diseases such as asthma and rheumatoid arthritis are characterised at the molecular level by chronically increased expression of multiple cytokines, chemokines, kinins and their receptors, adhesion molecules, and inflammatory enzymes such as inducible nitric oxide synthase (iNOS) and the inducible cyclooxygenase (COX-2). ${ }^{1}$ At the cellular level, inflamed regions show a substantial influx of various inflammatory cells, arterial dilation, increased blood flow, plasma protein leakage, and oedema whilst, in the case of chronic asthma, substantial remodelling of the airways is observed involving excessive smooth muscle proliferation. However, these parameters of inflammation are effectively reduced by treatment with glucocorticoids by both direct and indirect mechanisms. ${ }^{2}$ For example, the reduced eosinophilia following glucocorticoid treatment in asthmatic subjects arises by direct promotion of eosinophil apoptosis and indirectly by suppressing receptor expression and production of cytokines or growth factors. ${ }^{4}$ These include factors such as interleukin (IL)-3, IL-5, granulocyte-macrophage colony stimulating factor (GM-CSF), and eotaxin which are involved in eosinophil maturation, recruitment, and survival. Similarly, glucocorticoids reduce $\mathrm{T}$ cell proliferation and increase $\mathrm{T}$ cell apoptosis via mechanisms that Accepted for publication 1 March 2000

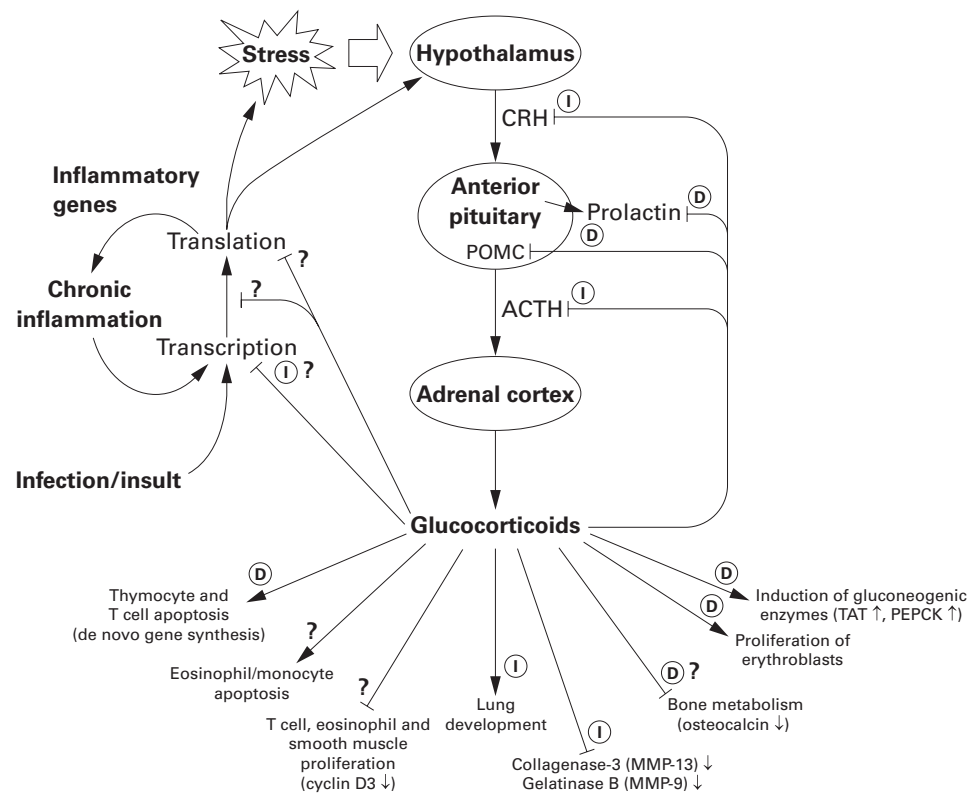

Figure 1 Effects of glucocorticoids on the hypothalamic-pituitary-adrenal (HPA) axis. This scheme shows the sites of synthesis and action of the main HPA hormones and the targets of glucocorticoid action (see text for details). Based on analysis of dimerisation defective mice many of the effects of glucocorticoids are labelled as either dependent on (D) or independent of (I) GR DNA binding. Question marks indicate uncertainty as to the mechanism of action. Abbreviations are to be found in the text. Adapted from Reichardt and Schutz. ${ }^{13}$ are at least partly the result of inhibition of the $\mathrm{T}$ cell growth factor, IL-2. ${ }^{5-8}$ Likewise, monocyte apoptosis is increased and influx of other infiltrating inflammatory cells is also repressed. ${ }^{29}$ Again, this is partly caused by reduced expression of adhesion molecules, both on migrating and target cells, as well as reduced expression of cytokines and chemokines from sites of inflammation.

Therapeutically, the ability to suppress a number of inflammatory indices makes glucocorticoids among the most potent antiinflammatory agents currently available for the treatment of chronic inflammatory diseases such as asthma. ${ }^{23}$ The clinical efficacy of synthetic glucocorticoids such as prednisolone or dexamethasone stems from their ability to mimic natural glucocorticosteroids. Bodily insults, including inflammation, pain, infection or even mental stress, lead to activation of the hypothalamic-pituitary-adrenal (HPA) axis. These stimuli cause excitation of the hypothalamus, which responds by releasing corticotropin releasing hormone (CRH) (also known as corticotropin releasing factor, CRF). CRH then acts on the anterior pituitary to induce synthesis and release of adrenocorticotropic hormone $(\mathrm{ACTH})$. ACTH in turn stimulates the adrenal cortex to release glucocorticoids such as cortisol. Once within the blood, cortisol is transported to target organs where it elicits numerous metabolic effects including increased blood glucose levels, stimulation of gluconeogenesis in the liver, and the mobilisation of both amino and fatty acids (fig 1). However, in addition to these metabolic effects, glucocorticoids are also potent endogenous immunological suppressors. Thus, whilst the anti-inflammatory power of synthetic glucocorticoids derives from endogenous anti-inflammatory mechanisms, the clinical usefulness of these drugs is limited by HPA insufficiency and effects on bone metabolism in addition to the metabolic effects listed above. In this respect, it is often stated that the metabolic effects of glucocorticoids result from increased transcription of genes such as tyrosine aminotransferase (TAT) and phoshoenolpyruvate carboxykinase (PEPCK), ${ }^{10-13}$ whereas the anti-inflammatory properties are attributed to negative transcriptional effects on inflammatory gene expression. ${ }^{12-14}$ However, this may not wholly be the case.

\section{Classical mechanisms of glucocorticoid action}

It is generally believed that most, if not all, the effects of glucocorticoids on cells are mediated via the glucocorticoid receptor (GR). This 777 amino acid protein was cloned in humans in 
A

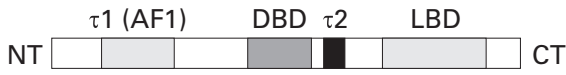

B

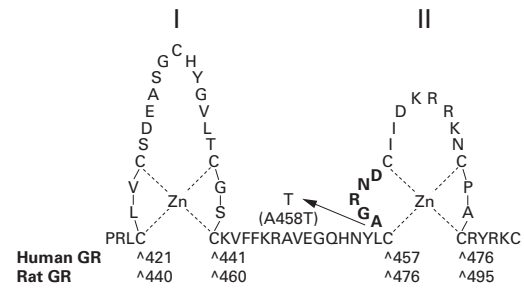

Figure 2 Structure of the glucocorticoid receptor. (A) Linear representation of the 777 amino acid glucocorticoid receptor showing the principal domains. $D B D=D N A$ binding domain; $L B D=$ ligand binding domain; $\tau 1$ and $\tau 2$ $=$ the two activation domains; $N T=$ amino terminal $; C T$ = carboxy terminal. (B) Enlargement of part of the DBD showing the amino acid sequence (single letter codes) of the two zinc fingers and the dimerisation loop (in bold).

Numbering of both the human and rat receptors is given. The A to T mutation at position 458 that gives rise to the dimerisation defective receptor is shown.

1985 and is a member of the superfamily of ligand regulated nuclear receptors. ${ }^{15}$ In common with other family members, GR has a modular structure whose principal functionstransactivation, DNA binding, and ligand binding - are localised to specific domains (fig 2A). ${ }^{16-19}$ In addition, alternative mRNA splicing results in a second GR isoform, GR $\beta$, that

Table 1 GRE and nGRE sites in glucocorticoid responsive genes

\begin{tabular}{llll}
\hline & Site & Position & Reference \\
\hline Consensus GRE & GGT ACA NNN TGT TCT & & 10,22 \\
Tyrosine aminotransferase & TGT ACA GGA TGT TCT & $-2509 /-2495$ & 10,23 \\
Metallothionein IIA & GGT ACA CTG TGT CCT & $-262 /-248$ & 24 \\
sgk & AGG ACA GAA TGT TCT & $-1 \mathrm{~kb}$ & 25 \\
Lysozyme & TGA TCC CTC TGT TCT & $-65 /-51$ & 26 \\
Osteocalcin (nGRE) & GGT ATA AAC AGT GCT & $-32 /-17$ & 27 \\
\hline
\end{tabular}

GRE = glucorticoid response elements; $\mathrm{nGRE}=$ negative GREs; $\mathrm{N}=$ any base.

Bases in bold conform to the consensus sequence.

The overlapping TATA box in the osteocalcin nGRE is underlined.

GR transactivation

A

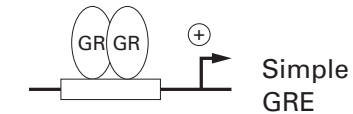

B

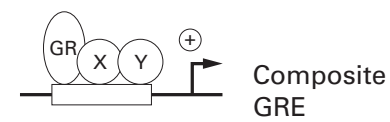

C

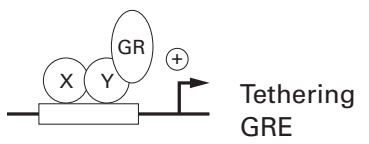

GR transrepression

D

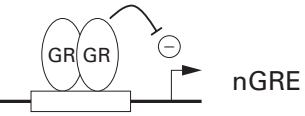

E

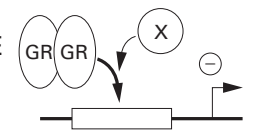

Competitive

$\mathrm{F}$

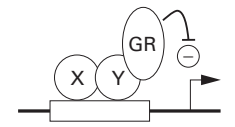
nGRE

Tethering nGRE

G

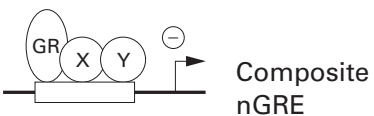

Figure 3 Models of glucocorticoid receptor transcriptional modulation. (A) Homodimers of GR bind cooperatively to classical GRE sites to activate transcription. (B) Interaction of $G R$ with a second transcription factor can activate transcription from composite binding sites in a manner that involves DNA binding of both factors. (C) Interaction of $G R$ with a second transcription factor may result in activation of transcription in a manner that does not require $D N A$ binding of GR. (D) Homodimers of $G R$ repress transcription from a simple $n G R E$. (E) At a competitive nGRE, binding of GR to the GRE site prevents binding of factors that are required for transcriptional activation and therefore causes transcriptional repression. $(F)$ Interaction of $G R$ with a second transcription factor may result in repression of transcription in a manner that does not require DNA binding by GR. $(G)$ Interaction of $G R$ with a second transcription factor can repress transcription from composite binding sites in a manner that involves DNA binding of both factors. is defective in steroid binding and can act as a dominant negative inhibitor of GRa..$^{152} 21$ However, this inhibition seems to require increased GR $\beta$ expression relative to GR $\alpha$ and a clear functional role has not yet been confirmed.

In the absence of ligand, GR is predominantly maintained in the cytoplasm as an inactive multi-protein complex. This consists of two hsp90 molecules plus a number of other proteins including the immunophilins p59 and calreticulin. ${ }^{19}$ Entry of glucocorticoids into the cell and subsequent binding to the ligand binding domain (LBD) of GR leads to a conformational change in the receptor. This causes dissociation of the multi-protein complex and allows nuclear translocation of GR by virtue of the nuclear localisation sequence within the DNA binding domain (DBD). Once within the nucleus, GR binds DNA sequences known as glucocorticoid response elements (GREs) to activate transcription of responsive genes (referred to as transactivation) (table 1, fig 3A). ${ }^{101922}$ Consistent with the palindromic nature of this motif, GR binds classical GRE sites cooperatively as a homodimer. This requires interactions between a group of five amino acids, known as the dimerisation or D loop, which is located within the DNA binding domain of each GR molecule and is essential for dimerisation and transcriptional activation (fig 2B). ${ }^{28}$

Genes that are known to be upregulated by glucocorticoids and play a role in resolution of inflammation include lipocortin I and p11/ calpactin binding protein which are both involved in suppressing release of arachidonic acid. $^{29} 30$ In addition, $\beta_{2}$-adrenoreceptors, ${ }^{31} 32$ secretory leucocyte protease inhibitor (SLPI), and the decoy IL-1 type II receptor are also upregulated by glucocorticoids. ${ }^{33} 34$ However, the induction kinetics for these proteins is generally slow-for example, over a 24-48 hour period-which suggests a role in the longer term anti-inflammatory effects of glucocorticoids. Thus, positive GR-dependent transcriptional mechanisms are not generally considered to explain the more rapid (0-12 hours) repressive effects of glucocorticoids on inflammatory genes. ${ }^{1214} 3536$

\section{Negative GREs and DNA binding \\ dependent transrepression}

Following on from the characterisation of positive GRE sequences was the postulation that the negative regulation of transcription (referred to as transrepression) by glucocorticoids occurred via negative GRE sites (nGRE). ${ }^{22}$ In practice, the existence of the nGRE has remained controversial as the consensus binding site is variable and they are only described for relatively few genes. ${ }^{132}$ One major physiological function of glucocorticoids is negative feedback inhibition of the HPA axis via repression of $\mathrm{CRH}$ and ACTH expression (fig 1). Indeed, one promoter to be described as repressed by glucocorticoids was that for the ACTH precursor gene, pro-opiomelanocortin (POMC) ${ }^{37}$ In this case, multimers of GR were shown to bind a nGRE and to cause repression 
of transcription..$^{38}$ Whilst the exact mechanism for this repression was not characterised, it was speculated to involve either protein-protein interactions with other factors on the POMC promoter or direct inhibition due to steric hindrance as a result of the close proximity to the TATA box and transcription start site (fig 3D and $\mathrm{E}$ ). However, in addition to conferring glucocorticoid dependent repression, this region is also necessary for basal POMC transcription and also overlaps with a site that is involved in promoter activation. ${ }^{39} 40$ Thus, binding of GR to the $\mathrm{nGRE}$ may block binding of positive factors and thereby cause transcriptional repression (fig 3E). ${ }^{40}$ In addition, subsequent studies have attributed the dexamethasone dependent repression of the POMC promoter to tethering mechanisms akin to that for AP-1 (below), as well as to repression of factors that are induced by $\mathrm{CRH}$ and mediate the CRH induction of POMC. ${ }^{41}$ Whilst initially these studies appear to be conflicting, it is important to remember that the conditions used and the method of analysis have a significant bearing on the outcome. It is therefore likely that negative regulation of POMC expression is, in fact, achieved by multiple transrepressive mechanisms (see below).

Another gene to be described as glucocorticoid repressible was that for the glycoprotein hormone $\alpha$ subunit gene. ${ }^{42}$ This promoter is positively regulated by the cAMP response element binding protein (CREB) and contains overlapping binding sites for both CREB and GR. Thus, DNA binding by GR is proposed to inhibit transcriptional activation directly by preventing binding of CREB (fig 3E). However, as this site shows only modest homology to a consensus GRE, it is possible that GR binding is weak and the repressive mechanism more truly resembles that for AP-1 (below). ${ }^{12} \mathrm{~A}$ further example of repression by virtue of overlapping sites for GR and other transcription factors is the osteocalcin promoter. ${ }^{27}{ }^{43}$ In this case a nGRE site was described that overlapped the TATA box (table 1). Thus, binding of GR may prevent subsequent binding of the basal transcription factor, TATA binding protein (TBP). As TBP plays an important role in recruitment of RNA polymerase II to the TATA box, ${ }^{44}$ this effect will result in transcriptional repression. Similarly, a region in the bovine prolactin gene that binds GR and confers nGRE activity also acts as constitutive positive enhancer. ${ }^{45}$ Thus GR dependent repression could involve competition between factors that bind this site or neutralisation of positive activation functions by the additional binding of GR to the nGRE (fig 3D and E). In each of these cases DNA binding by GR is required for repression (fig 1 ).

Transrepression without DNA binding Many inflammatory genes that are repressed by glucocorticoids are transcriptionally regulated by factors such as nuclear factor- $\kappa \mathrm{B}(\mathrm{NF}-\kappa \mathrm{B})$ and $\mathrm{AP}-1 .{ }^{3}{ }^{14}$ As nGRE sites are not generally found in the promoters of inflammatory genes, alternative mechanisms are proposed to account for the glucocorticoid dependent repres- sion of these genes. One such mechanism is thought to arise from interaction between GR and transcriptional activators. As this effect does not require direct binding of GR to DNA, the term "tethering GRE" is often used to describe these elements (fig 3F). This phenomenon was first described for AP-1 and was thought to involve direct protein-protein interactions between GR and AP-1. ${ }^{46-48}$ Functionally, the consequence of these interactions is mutual repression of both AP-1 and GR dependent transcription. ${ }^{46-48}$ Initially, reduced binding to the respective DNA recognition sites of each factor, as a result of interaction with the other, was thought to mediate this effect. ${ }^{46}{ }^{48}$ However, no change in AP-1 DNA binding in nuclear extracts or in vivo by DNA foot printing was observed in glucocorticoid treated cells, indicating that GR mediated repression occurs via a direct effect on transcriptional activation. ${ }^{4749}$

Like AP-1, glucocorticoids are able to repress the transcriptional activation by $\mathrm{NF}-\kappa \mathrm{B}$ via a direct interaction of GR with $\mathrm{NF}-\kappa \mathrm{B} .{ }^{50} 51$ Again, this interaction was initially thought to prevent $\mathrm{NF}-\kappa \mathrm{B}$ from binding to its cognate recognition sites and thereby cause repression of transcription. ${ }^{51}{ }^{52}$ In addition, an alternative mechanism of repression of $\mathrm{NF}-\kappa \mathrm{B}$ by dexamethasone was proposed..$^{53}$ This involved upregulation of the cytoplasmic NF- $\mathrm{NB}$ inhibitor, I $\mathrm{B} \alpha$, to prevent nuclear translocation and DNA binding of $N F-\kappa B$ by retention of $N F-\kappa B$ heterodimers in the cytoplasm. However, a number of problems exist with this explanation. In most cell types induction of NF- $\mathrm{NB}$ by stimuli such as IL-1 $\beta$ or tumour necrosis factor (TNF) $-\alpha$ results in a total loss of $\mathrm{I} \kappa \mathrm{B} \alpha$ within 5-10 minutes. ${ }^{55}$ Thus, even highly elevated levels of I $\mathrm{B} \alpha$ protein would only be expected to prevent NF- $\kappa \mathrm{B}$ activation temporarily. Furthermore, as the I $\kappa B \alpha$ gene is itself regulated by $\mathrm{NF}-\kappa \mathrm{B}$, reduced $\mathrm{NF}-\kappa \mathrm{B}$ activity may be expected to reduce $\mathrm{I} \kappa \mathrm{B} \alpha$ promoter activity and, indeed, this effect has recently been reported. ${ }^{56}$ Finally, at times that are most relevant to inhibition of inflammatory gene transcription - that is, shortly ( $<2$ hours) after stimulation-dexamethasone has little or no effect on induction of NF- $\mathrm{NB}$ DNA binding by TNF- $\alpha$, lipopolysaccharide (LPS), or IL- $1 \beta$ in endothelial or epithelial cells. ${ }^{55-60}$ In addition, the above studies failed to show any substantial increases in I $\kappa \mathrm{B} \alpha$ expression as a result of glucocorticoid treatment. Notwithstanding this, experimental conditions involving longer incubations in the presence of glucocorticoid-for example, after six hours of co-treatment with the stimulus or extended pretreatment with glucocorticoid-may cause repression of NF- $\kappa B$ DNA binding. ${ }^{5561}$ However, these observations, whilst confirming the existence of such repressive mechanisms, have little bearing on the immediate repression of proinflammatory genes and probably relate to a longer term dampening effect of glucocorticoids on inflammatory processes. This conclusion is supported by Heck et $a l^{62}$ who showed that any glucocorticoid dependent increase in $\mathrm{I} \kappa \mathrm{B} \alpha$ synthesis could be dissociated from 
repression of gene transcription and was neither required nor sufficient for downregulation of NF- $\mathrm{NB}$ transcriptional activity. Consequently, the role of GR in the repression of $\mathrm{NF}-\kappa \mathrm{B}$ DNA binding and induction of $\mathrm{I} \kappa \mathrm{B} \alpha$ may be variable and is probably dependent on the cell type and stimulus. It therefore appears that repression of NF- $\mathrm{KB}$ dependent transcription, like that for AP-1, primarily occurs subsequent to or downstream of DNA binding and involves GR interfering with the transcriptional activation process itself. ${ }^{63}$

\section{Multiple transrepressive mechanisms may act in concert}

In considering the various repressive mechanisms involving standard, competitive, tethering, or other nGRE sites, it is worth noting that these schemes could be viewed as variations or continuations of essentially similar mechanisms (fig 3D-G). In a given experimental context, the investigator will generally only detect the predominant mechanism involved. Thus, for example, in the case of competition for binding sites (fig 3E), GR directly binds DNA and prevents binding of factors that are necessary for transcriptional activation. However, this binding will undoubtedly involve steric (or other) hindrance of additional (unknown) factors, which may also contribute to the repression in a manner depicted in fig 3D. In addition, binding of GR to a competitive nGRE (or any other site) is also to some extent stabilised by interactions with surrounding factors that are themselves in contact with the DNA. The repressive interaction will therefore also show characteristics of a tethering or composite type nGRE (fig $3 \mathrm{~F}$ and $\mathrm{G}$ ). Likewise, the situation where GR binds strongly to DNA (fig $3 \mathrm{D}$ or $\mathrm{E}$ ) and is stabilised by weak interactions can be contrasted with a situation where GR shows very weak or no interaction with DNA and is tethered in position by interactions with other DNA binding factors (fig 3F). Furthermore, it is possible to view the composite nGRE as an intermediate between these two extremes. Thus, at nGRE sites, GR prevents the positive transcriptional response via mechanisms that are likely to involve multiple protein-protein interactions that prevent activation of the basal transcription complex by activating transcription factors or co-factors. In any given case it is likely that a combination of these mechanisms will contribute to the overall (trans-) repressive effect (fig 3D-G).

\section{Mutuality of transcriptional repression}

One feature that is common to GR mediated repression of both $\mathrm{AP}-1-$ and $\mathrm{NF}-\kappa \mathrm{B}$ dependent transcription is the mutuality of the effect. Not only is GR capable of repressing AP-1 and $\mathrm{NF}-\kappa \mathrm{B}$ dependent transcription, but AP-1 and $\mathrm{NF}-\kappa \mathrm{B}$ may also repress GR dependent transcription. ${ }^{46-48505164}$ One explanation for this effect is that GR competes with AP-1 or $\mathrm{NF}-\kappa \mathrm{B}$ for components of the transcriptional apparatus that are limiting and necessary for gene activation. In this respect the transcriptional co-activator molecule, CREB binding protein (CBP), which plays a part in the activation of transcription by numerous transcription factors/transcriptional activators, has attracted much attention. ${ }^{65}{ }^{66}$ This large protein is capable of binding to and co-activating with many activators including CREB, AP-1, STATs, and NF- $\mathrm{BB}$, as well as steroid hormone receptors such as GR, progesterone receptors, thyroid hormone receptors, and the retinoid receptors. ${ }^{65}{ }^{67-71}$ The function of CBP and similar proteins is currently under investigation but is thought to involve linking transcriptional activators to the basal transcription complex. ${ }^{71}$ In addition, CBP possesses an intrinsic histone acetytransferase activity. ${ }^{72}$ Thus, recruitment to the promoter of proteins such as CBP and p300/CBP associated factor ( $/ \mathrm{CAF})$, which binds to CBP and also shows histone acetyltransferase activity ${ }^{74}{ }^{75}$ will cause acetylation of histone proteins and result in derepression of the chromatin structure. ${ }^{73}$ This facilitates transcription by allowing access to and unwinding of the DNA by components of the transcriptional machinery and represents a further regulatory control point. ${ }^{7176}$ In this respect, members of the nuclear hormone receptor family that are involved in transcriptional repression have been shown to exist in a repressor complex along with histone deacetylase activities. ${ }^{77}$ If this observation also holds true for GR, then recruitment of histone deacetylases to the promoters of inflammatory genes may result in loss of acetyl groups from the core histone proteins. This would lead to transcriptional silencing and would provide a novel mechanism whereby glucocorticoids can repress transcription.

\section{The concept of disassociating steroids}

Leading on from the belief that the predominant anti-inflammatory effects of glucocorticoids derive from inhibition of transcription (transrepression), whereas the metabolic effects derive from positive transcriptional effects (transactivation), a number of investigators have sought to separate these functions using various mutant GR constructs and specialised "dissociating" steroids. Deletion studies with mutant GR constructs have shown that the steroid binding domain, the activation domains, and a functional DNA binding domain are necessary for efficient hormone inducible transcription from GRE containing promoters. ${ }^{17}$ However, the ability to repress an AP-1-dependent promoter (tethering type transrepression) was localised to the DNA binding domain (DBD) of GR. ${ }^{64}$ Indeed, a number of point mutations in the DBD were identified that maintained the ability to transactivate, but had lost the ability to transrepress, AP-1 mediated transcription. ${ }^{64}$ Furthermore, these two functions were clearly distinguished by the D loop mutant, A458T (fig 2B). ${ }^{64}$ This mutation results in a protein that is defective in cooperative dimerisation and is unable to bind classical GRE sites or activate GR dependent transcription from GRE containing promoters. ${ }^{28}{ }^{64}$ As the ability to transrepress AP-1 dependent transcription was unaffected, these data support the hypothesis that direct binding of GR to DNA is not required for 
transrepression of $\mathrm{AP}-1$ dependent transcription. Likewise, additional mutants of this region also showed the ability to transrepress both $\mathrm{AP}-1$ and $\mathrm{NF}-\kappa \mathrm{B}$ dependent transcription and were again unable to activate GRE dependent transcription. ${ }^{62} 6478$

The above studies have clearly shown that some of the repressive and activating functions of GR may be dissociated at the protein level. The question that then arises is whether these functions can be differentially activated by steroid ligands. From a therapeutic point of view, this could have great significance if, as mentioned above, the repressive functions of GR mediate the anti-inflammatory effects whilst gene activation is responsible for the metabolic, and therefore undesirable, effects of glucocorticoids. Some degree of functional separation is achieved by steroid antagonists such as RU38486 (RU486). This compound shows little ability to transactivate GR dependent transcription..$^{62}{ }^{64}{ }^{79}$ However, in reporter assays RU486 repressed AP-1 dependent transcription to about $50-70 \%$ that for dexamethasone, ${ }^{649}$ whilst repression of $\mathrm{NF}-\kappa \mathrm{B}$ dependent transcription was no more than $30 \%$ that for dexamethasone. ${ }^{62} 78$ In addition, the steroids ZK98296 and ZK98299 were identified which showed little ability to transactivate, yet retained $50-80 \%$ of the ability of dexamethasone to repress an AP-1 dependent reporter. ${ }^{64}$ Likewise, at $100 \mathrm{nM}$ the glucocorticoids RU24782, RU24858, and RU40066 showed no more than $35 \%$ of the ability of dexamethasone to transactivate a GRE dependent reporter, whilst retaining at least 58\% of the capacity of dexamethasone to transrepress AP-1 dependent promoters. ${ }^{79}$ Interestingly, in a monocytic cell line RU24782, RU24858, and RU40066 were found to be poor activators of the glucocorticoid inducible TAT gene but were $70-95 \%$ as effective as dexamethasone in suppressing LPS induced release of IL-1 $\beta .{ }^{79}$ Furthermore, in a cotton pellet granuloma model of inflammation both RU24782 and RU24858 displayed antiinflammatory properties that were similar to prednisolone, suggesting that transrepressive mechanisms play a significant antiinflammatory role in this model. ${ }^{79}$ Similar approaches were also used to dissociate transrepression of $\mathrm{NF}-\kappa \mathrm{B}$ from GR dependent transactivation. ${ }^{62}$ In this study the glucocorticoids ZK57740 and ZK077945, which are not anti-inflammatory, showed an impaired ability to transrepress an $\mathrm{NF}-\kappa \mathrm{B}$ dependent reporter but were fully functional in GRE dependent transactivation assays. ${ }^{62}$ Conversely, the dissociated glucocorticoids RU24782 and RU24858 were nearly as effective as dexamethasone in the repression of $\mathrm{NF}-\kappa \mathrm{B}$ dependent transcription, IL- 6 promoter activity, and IL-6 expression, whilst remaining nonfunctional in GRE dependent transactivation assays. ${ }^{57}$ The above studies suggest that transactivation defective steroids may not induce metabolic genes, and may not therefore give rise to Cushing type symptoms, yet may still illicit useful anti-inflammatory effects. However, other undesirable effects on, for example, bone metabolism may also be mediated via transrepressive mechanisms involving negatively regulated genes such as osteocalcin (fig 1). ${ }^{80}{ }^{81}$ Indeed, preliminary data suggest that, whilst the dissociated steroid RU24858 showed anti-inflammatory properties in vivo, effects on bone metabolism were similar to glucocorticoids such as budesonide or prednisolone. ${ }^{82}$ Consequently, whilst the ability of "dissociating" glucocorticoids to separate GR functions can be demonstrated in reporter assays, considerable further work is required to establish whether these compounds can be effectively used in vivo to produce anti-inflammatory effects with reduced side effects.

\section{Gene knockouts and the dim mouse}

One powerful tool for studying genetically engineered proteins in an in vivo context is the use of transgenic mice. Mice homozygous for a targeted disruption of the GR gene $\left(\mathrm{GR}^{-1}\right)$ die within a few hours of birth due to respiratory failure as a result of severely impaired lung development. ${ }^{83}$ In addition, these mice show substantially reduced expression of gluconeogenic enzymes such as glucose-6-phosphatase and amino acid catabolising genes such as tyrosine aminotransferase (TAT) and serine dehydrogenase. At the level of the HPA axis, $\mathrm{GR}^{-/}$mice show 20 times higher levels of ACTH and 2-3 times higher levels of circulating corticosterone. Similarly, $\mathrm{CRH}$ expression in the hypothalamus of $\mathrm{GR}^{-/}$mice was about five times greater than that in wild type mice. ${ }^{84}$ These effects are consistent with impaired negative feedback inhibition of the HPA axis and thus confirm the role of GR in these processes. To gain further insights into the mechanisms of GR action, a line of transgenic mice was established in which the wild type GR was replaced with a receptor containing the A458T mutation in the D loop (fig 2B). ${ }^{85}$ As this receptor is unable to homodimerise, it is defective in DNA binding and transcriptional activation from classical GRE sites whilst transrepressive effects via tethering interactions with $\mathrm{AP}-1$ and NF- $\mathrm{KB}$ are unaffected. ${ }^{28}{ }^{64}$ Consequently, mice homozygous for the A458T mutation, referred to as $\mathrm{GR}^{\text {dim/dim }}$, offer the opportunity to test in vivo for effects dependent or independent of DNA binding by GR. ${ }^{13}$ The first significant observation was that, in contrast to $\mathrm{GR}^{-1-}$ mice, $\mathrm{GR}^{\text {dim/dim }}$ mice survive to term and are apparently healthy. ${ }^{85}$ This immediately implicates functions that are independent of GR DNA binding in normal lung development and other physiological processes (fig 1). Significantly, there was no induction of the TAT gene or other gluconeogenic genes in $\mathrm{GR}^{\text {dim/dim }}$ mice, indicating that the reporter data were physiologically relevant and that GR dimerisation and DNA binding is necessary in vivo for GR dependent transactivation of these genes. To analyse the effect on tethering mechanisms of transrepression, primary fibroblasts from wild type and $\mathrm{GR}^{\text {dim/dim }}$ mice were stimulated with phorbol ester and northern analysis performed for the AP-1 dependent genes, collagenase-3, and gelatinase $B$. In both 
wild type and $\mathrm{GR}^{\text {dim/dim }}$ mice a substantial induction of these two genes was observed and in each case this was repressed by $40-45 \%$ following treatment with dexamethasone. ${ }^{85}$ This indicates that the mechanisms involved in the dexamethasone dependent repression of these mRNAs are independent of GR DNA binding (fig 1).

To examine the role of DNA binding in other GR dependent processes, analysis of the HPA axis was also performed in $\mathrm{GR}^{\text {dim/dim }}$ mice. In the median eminence, which is the site of $\mathrm{CRH}$ release into the blood, there was no difference in $\mathrm{CRH}$ expression between wild type and $\mathrm{GR}^{\text {dimldim }}$ mice, whereas $\mathrm{GR}^{-/-}$mice showed increased CRH expression. ${ }^{83}{ }^{85}$ In contrast, $\mathrm{GR}^{\text {dim/dim }}$ mice showed markedly increased mRNA expression of POMC (the ACTH precursor) mRNA in the anterior lobe of the pituitary, whilst ACTH protein expression itself was raised 2.2-fold. Taken together these data indicate that negative feedback control of $\mathrm{CRH}$ expression involves effects that are independent of GR DNA binding, whilst mRNA expression of POMC is negatively controlled by mechanisms that are dependent on DNA binding of GR. Furthermore, the fact that POMC mRNA expression was strongly upregulated in $\mathrm{GR}^{\text {dim/dim }}$ mice, whereas ACTH protein was only increased about twofold, suggests differential control of mRNA and protein expression involving both GR DNA binding dependent and independent mechanisms, respectively. Similarly, expression of prolactin, a gene that is negatively regulated by $\mathrm{GR}$, was also increased in both $\mathrm{GR}^{-/}$and $\mathrm{GR}^{\text {dim/dim }}$ mice. ${ }^{85}$ These data suggest that DNA binding dependent effects are involved in the negative regulation of POMC and prolactin and this is consistent with the previous characterisation of nGRE sites in the promoters of these genes. ${ }^{3845}$

Thus, in vivo analysis of wild type, $\mathrm{GR}^{-/}$, and $\mathrm{GR}^{\text {dim/dim }}$ mice confirms the in vitro data by demonstrating separation of DNA binding dependent and independent functions. Furthermore, it appears that transrepression involving tethering mechanisms remains intact, at least in respect of AP-1 dependent genes. Further analyses are now required to examine the ability of these mice to suppress various inflammatory responses in response to glucocorticoids as well as to determine the extent of any other undesirable effects. In particular, it is now important to use these mice to characterise the effect of glucocorticoids on the repression of inflammatory genes, including cytokines and adhesion molecules, that are regulated by transcription factors such as $\mathrm{NF}-\kappa \mathrm{B}, \mathrm{C} / \mathrm{EBP}, \mathrm{CREB}$, as well as AP-1. Such studies will shed light on the mechanisms of gene repression and, in particular, the relative contribution of DNA binding dependent and independent effects of GR action. In addition, these studies will act as a validation exercise for the possible therapeutic benefits of second generation dissociating glucocorticoids.
Post-transcriptional and translational targets of glucocorticoid action

So far this review has focused on the transcriptional mechanisms by which glucocorticoids regulate the expression of responsive genes. However, correctly regulated gene expression requires the coordinated control of transcriptional (that is, the rate of gene transcription), post-transcriptional (for example, mRNA stability), translational (that is, protein synthesis), and post-translational (for example, protein processing, modification or degradation) events. In addition, other post-translational processes involving, for example, intracellular localisation or, in the case of cytokines, secretion may also act as control points. Given this myriad of mechanisms involved in the regulation of gene expression, it is likely that a number, if not all, of these processes are also targets of glucocorticoid action.

In recent years it has become increasingly apparent that many genes are regulated to a substantial degree by post-transcriptional and translational mechanisms. ${ }^{86-88}$ For example, the 3' untranslated region (UTR) of GM-CSF mRNA contains a number of repeated AU-rich motifs that play a part in mRNA destabilising and translational blockage. ${ }^{89-91}$ The potential for regulation at this level is illustrated by the fact that proteins binding to these sites can regulate GM-CSF mRNA turnover, whilst mutation of these AU sites enhances GM-CSF expression. ${ }^{92}{ }^{93}$ In addition, similar AU-rich elements have been described in the 3' UTRs of numerous cytokine, lymphokine, growth factor, and transcription factor genes, suggesting that similar mechanisms of regulation are, in fact, widespread. ${ }^{94}$ In this respect, steady state mRNA levels of IL-11 in bone marrow stromal cells were highly inducible by IL- $1 \alpha$ and this increase was exclusively attributed to mRNA stabilisation. $^{95}$ Likewise, post-transcriptional mechanisms have been documented in the induction of numerous inflammatory genes including IL-1 $\beta$, IL-2, IL-6, IL-8 and COX $-2 .{ }^{96-102}$

As a model system we have studied COX-2 expression and prostaglandin $\mathrm{E}_{2}\left(\mathrm{PGE}_{2}\right)$ release from human epithelial-like A549 cells. These cells, in common with primary bronchial epithelial cells, produce increased levels of prostaglandins in response to proinflammatory cytokines such as IL- $1 \beta$ and, in both cases, the response is repressed by dexamethasone. ${ }^{103}{ }^{104}$ This induction is at least in part the result of the transcriptional induction of COX-2 by transcription factors such as NF- $\kappa \mathrm{B}$, as well as posttranscriptional mechanisms. ${ }^{101}{ }^{105}$ In these cells repression of COX-2 expression by dexamethasone was mediated by both transcriptional and post-transcriptional mechanisms. ${ }^{106}$ Dexamethasone reduced the rate of COX-2 transcription by no more than $50 \%$ and this correlated closely with the effect on $\mathrm{NF}-\kappa \mathrm{B}$ dependent transcription in these cells. ${ }^{55}$ However, as repression of COX-2 protein by dexamethasone was almost absolute, these data clearly implicate the existence of additional repressive mechanisms. In this system dexamethasone decreased COX-2 mRNA stability via mechanisms that 


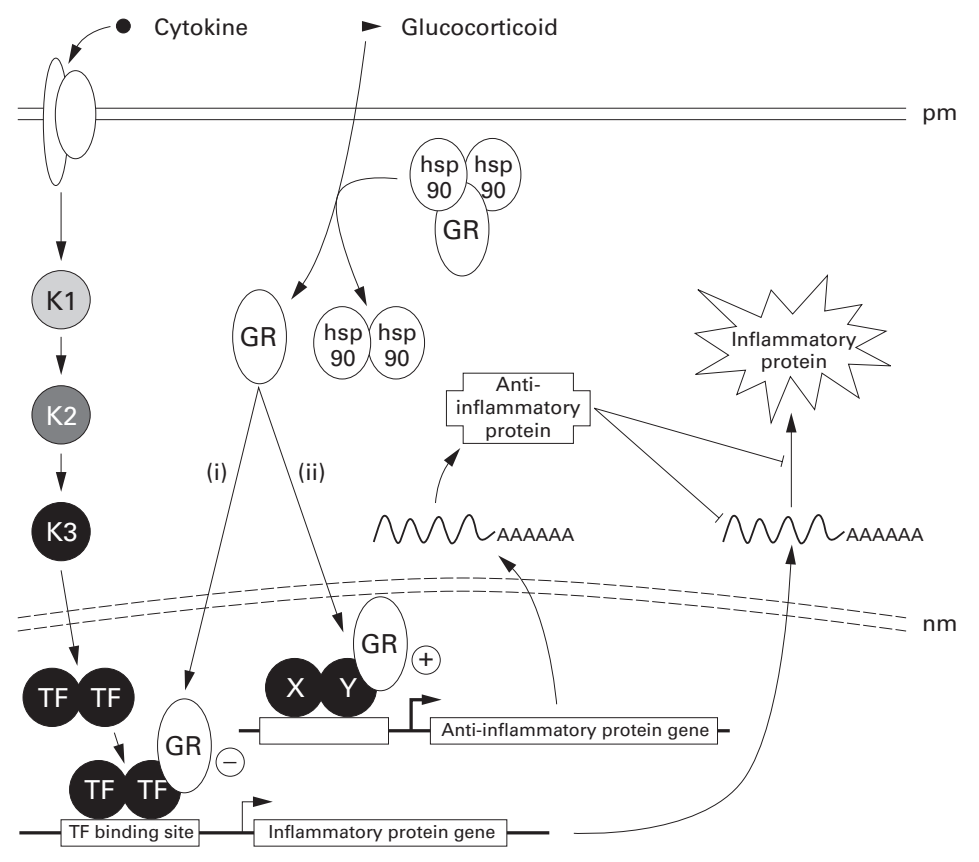

Figure 4 A model for glucocorticoid dependent repression of proinflammatory genes. $A$ generalised inflammatory cascade is shown. Cytokine binding to its cognate receptor

localised in the plasma membrane ( $p m$ ) leads to activation of a kinase cascade consisting of kinases 1, 2, and 3 (K1, K2, and K3). K3 translocates across the nuclear membrane (nm) and then phosphorylates the transcription factor (TF) which actives transcription of an inflammatory protein gene. This leads to $m R N A$ synthesis (transcription) and protein synthesis (translation) of the inflammatory protein. Binding of glucocorticoid to the glucocorticoid receptor (GE) leads to dissociation of the heat shock proteins (hsp90) and translocation of GR to the nucleus. (i) GR may bind $T F$ (for example $N F-\kappa B$ or $A P-1$ ) to repress activated transcription via tethering type interactions. (ii) Alternatively, it is hypothesised that $G R$ interacts with other factors $(X, Y)$ to activate gene transcription of anti-inflammatory genes. These anti-inflammatory genes are further hypothesised to promote $m R N A$ degradation and/or repress translation of inflammatory genes.

involved preferential loss of polyadenylated mRNA. ${ }^{106}$ Interestingly, as repression of mRNA expression by thyroid hormone receptors may also involve the loss of poly(A) tails and the length of the poly(A) tail can have a profound effect on mRNA translation, ${ }^{86} 107108$ these findings could represent a novel mechanism by which nuclear hormone receptors regulate gene expression. In A549 cells this effect required ongoing RNA and protein synthesis, suggesting the need for dexamethasone inducible gene synthesis. ${ }^{106}$ Furthermore, dexamethasone was highly effective in preventing COX-2 protein expression, even when added a substantial time after the IL-1 $\beta$ stimulus. At these later times, COX-2 mRNA levels are highly increased and inhibition of RNA transcription at these times was ineffective in inhibiting COX-2 expression. These data therefore strongly implicate posttranscriptional and/or translational mechanisms as overriding mechanisms of dexamethasone dependent repression. ${ }^{106}$ In support of this hypothesis, similar dexamethasone dependent effects have also been reported for COX-2, IL-1 $\beta$, GM-CSF, IL-6, IL-8, interferon $\gamma$, and iNOS in various other cells types. ${ }^{102}{ }^{109-115}$ In the case of TNF- $\alpha$, dexamethasone has been shown to act at the level of translation. ${ }^{116}$ This correlates with the substantial degree of regulatory control that occurs at the level of TNF- $\alpha$ mRNA translation via mechanisms which are thought to involve binding of specific proteins to the AU-rich region within the 3' UTR as well as by increases in the poly(A) length. ${ }^{108}{ }^{117-119}$ Further- more, the suggestion that glucocorticoids act more globally at the level of translation is also supported by the finding that dexamethasone can suppress the synthesis of many ribosomal proteins and translation initiation factors. ${ }^{120}$ Consistent with the above findings, we have previously found that dexamethasone was ineffective in repressing the activation of GM-CSF promoter constructs in human $\mathrm{T}$ cells. ${ }^{121} \mathrm{As}$ GM-CSF release was totally inhibited, these experiments again implicate a significant role for post-transcriptional or translational mechanisms of action. One further example of post-transcriptional downregulation by dexamethasone has been shown for monocyte chemoattractant protein 1 (MCP-1). ${ }^{122}$ In this case the dexamethasone dependent destabilising activity was found not to require new protein or RNA synthesis. Taken together, these findings indicate that post-transcriptional and/or translational mechanisms of control represent potent glucocorticoid effector functions. Furthermore, the dependence on ongoing transcription or translation indicates that many of these effects involve transcriptional activation and therefore presumably the transactivation functions of GR. ${ }^{102} 106112$ A model for glucocorticoid dependent repression of inflammatory genes is therefore proposed involving both the transrepressive and transactivating functions of GR (fig 4).

Positive transcriptional effects of glucocorticoids in immunosuppression It was noted above that glucocorticoids induce apoptosis of both $\mathrm{T}$ cells and eosinophils. In this respect entry of the cell to the programmed cell death pathway is an active process and requires a variety of newly synthesised proteins. ${ }^{123}$ Likewise, dexamethasone dependent protein synthesis is implicated in cell death and the DNA fragmentation that precedes cell death in $\mathrm{T}$ cell apoptosis that has been induced by dexamethasone. ${ }^{123-126}$ This role for dexamethasone dependent gene synthesis is further substantiated by the finding that thymocytes from both homozygous $\mathrm{GR}^{-/-}$and $\mathrm{GR}^{\text {dim/dim }}$ mice are resistant to dexamethasone induced apoptosis. $^{8385}$

Another prominent effect of glucocorticoids on $\mathrm{T}$ cells and other cells is the arrest of proliferation by blocking cell cycle progression at $G_{0} / G_{1}$. Unlike apoptosis, inhibition of $\mathrm{T}$ cell proliferation by glucocorticoids occurs at least in part by repression of cell cycle genes such as the G1 progression factor, cyclin D3. ${ }^{127}$ Remarkably, this repression of cyclin D3 occurs via a rapid post-transcriptional repression mechanism which, like many of the inflammatory genes (above), appears to require the synthesis of a glucocorticoid induced protein or proteins. ${ }^{127}$ Thus, once again, detailed molecular analysis reveals strong evidence for substantive immunosuppressive effects of glucocorticoids being mediated via positive transcriptional mechanisms.

Other transcriptional responses mediated by glucocorticoids

In the preceding sections we have seen how glucocorticoids, acting via GR, can positively 
regulate transcription from GRE sites and negatively regulate transcription via a variety of mechanisms including nGRE and tethering sites. However, a number of other transcription modulating activities of GR exist which may result in biologically significant effects. One area that is frequently overlooked is the ability of GR to act synergistically with AP-1 or the AP-1 components c-Fos and c-Jun from composite elements (fig 3B). ${ }^{128} 129$ This type of "composite" DNA binding element contains binding sites for GR as well as factors such as $\mathrm{AP}-1$ (fig 3B). Furthermore, the functional outcome of factors binding to these sites depends very much on the cellular environment. Thus, dexamethasone may activate or repress transcription from these elements depending on the cell type. ${ }^{128}$ Physiologically, these effects resemble that for genes such as PEPCK, which may be upregulated or downregulated by glucocorticoids depending on the cell type. ${ }^{128}$ Similarly, paired simple GRE and $\mathrm{AP}-1$ sites can result in synergistic activation of transcriptional responses in a manner that is dependent on the spacing between the two elements. ${ }^{130}$ Likewise, similar cooperative effects have been shown between GRE sites and other transcription factor binding sites. ${ }^{131-133}$ One group of factors that is involved in the activation of glucocorticoid dependent transcription is the CCAAT/enhancer binding proteins $(\mathrm{C} / \mathrm{EBP}) .{ }^{132}$ Indeed, $\mathrm{C} / \mathrm{EBP}$ elements are strongly implicated in the glucocorticoid induction of genes such as the rat arginase gene or the PEPCK gene via mechanisms that involve induction of $\mathrm{C} / \mathrm{EBP} \beta .{ }^{11}{ }^{134}$ In addition, activation of the PEPCK gene by glucocorticoids and cAMP has also been proposed to involve interaction between GR and CREB. ${ }^{135}$ Likewise, the synergistic induction of the rat serine protease inhibitor- 3 gene by IL- 6 and dexamethasone appears to involve interaction of GR with Stat3 and C/EBP. ${ }^{136}$ Similarly, the transcription factor Stat 5 is capable of synergy with GR in a manner that involves direct interaction between Stat5 and GR and does not seem to require GR DNA binding (fig 3C). ${ }^{137} 138$

The existence of the above interactions raises the possibility that, in addition to effects in respect of acute phase genes in the liver, these types of response may also play a role in the anti-inflammatory actions of glucocorticoids. At present these interactions have not been examined using dissociated steroids or the various transactivation and transrepression defective GR mutants. Consequently, we do not currently understand the mechanisms behind these effects nor can we guess the role that these processes may play in the antiinflammatory actions of glucocorticoids. However, it is tempting to speculate that putative glucocorticoid inducible genes, which are involved in the post-transcriptional repression of inflammatory genes, may display similar responses.

\section{Future directions}

In recent years a number of glucocorticoid inducible signalling proteins such as the serum and glucocorticoid inducible kinase $s g k,{ }^{25}$ the glucocorticoid induced diacylglycerol kinase, ${ }^{139}$ and the small Ras-like GTPase, dexras $1^{140}$ have been identified. These and other similar proteins may be expected to elicit direct, albeit as yet uncharacterised, dexamethasone dependent signalling effects. Furthermore, it is likely that additional glucocorticoid inducible genes involved in signal transduction will be characterised and collectively these new signalling proteins will lead to novel glucocorticoid dependent responses. Two events that are dramatically altering our ability to characterise changes in gene expression at the mRNA level are the revolution in microarray or gene chip technology and the imminent completion of the human genome project. In this respect the sequencing of human chromosome 22 was recently reported. ${ }^{141}$ When complete, the human genome project, in conjunction with the refinement of current expressed sequence tag site (EST) data bases, will provide investigators with a virtually complete list of human genes. This information can then be combined with array or chip technology to analyse thousands, tens of thousands or, ultimately, hundreds of thousand of genes for changes in mRNA expression following a given stimulus or in a given cell type. ${ }^{142}$ Thus, the full RNA characterisation, in terms of both positive and negative changes in gene expression, will be possible following glucocorticoid treatment. Such analyses may allow the molecular characterisation of individuals who fail to respond to steroids and could lead to individual specific therapeutic approaches. In addition, the identification of genes involved in the glucocorticoid response will facilitate the identification of responses that are desirable for antiinflammatory effects and those that are undesirable - for example, those that promote bone metabolism or give rise to Cushing's syndrome.

In conclusion, many of the transcriptional effects of glucocorticoids mediated by GR, including upregulation of gene transcription via "classical" GRE sites and repression of transcription via nGRE and tethering type mechanisms, are currently well characterised. These mechanisms account for a number of positive effects of glucocorticoids including various metabolic effects, as well as certain anti-inflammatory effects - for example, transrepression via interactions with transcription factors such as $\mathrm{AP}-1$ and $\mathrm{NF}-\kappa \mathrm{B}$. However, these mechanisms alone do not appear to explain the full ability of glucocorticoids to repress many inflammatory genes. In this respect, an increasing number of studies have documented the existence of posttranscriptional mechanisms of repression that appear to play a significant, if not over-riding, role in glucocorticoid dependent gene repression (fig 4). Furthermore, positive transcriptional mechanisms have been strongly implicated in a number of immunosuppressive effects of glucocorticoids, including posttranscriptional repression, and it is possible that these may be mediated via novel interactions between GR and transcriptional activa- 
tors (fig 4). The further characterisation of these positive (and negative) transcriptional effects will be greatly facilitated by microarray expression analysis and these strategies can be expected to result in the definition, in terms of changes in gene expression, of the desirable anti-inflammatory properties of glucocorticoids. Finally, these approaches combined with a continued mutational analysis of GR may eventually lead to the characterisation of new classes of glucocorticoids that retain potent anti-inflammatory effects whilst minimising unwanted effects.

The author wishes to thank Donna Slater, Karl Staples, and John Matthews for their critical evaluation of the manuscript.

1 Barnes PJ. Pathophysiology of asthma. In: Barnes PJ, Rodger IW, Thomson NC, eds. Asthma: Basic mechanisms and clinical management. London: Academic Prress, 1998: 487-506.

2 Barnes PJ. Glucocorticosteroids. In: Barnes PJ, Rodger IW, Thomson NC, eds. Asthma: Basic mechanisms and clinical management. London: Academic Press, 1998: 725-66.

3 Barnes PJ. Therapeutic strategies for allergic diseases. Nature 1999;402(Suppl):B31-8.

4 Giembycz MA, Lindsay MA. Pharmacology of the eosinoGiembycz MA, Lindsay MA. Pharmaco
phil. Pharmacol Rev 1999;51:213-339.

5 King KL, Cidlowski JA. Cell cycle regulation and apoptosis. Anпu Rev Physiol 1998;60:601-17.

6 Lanza L, Scudeletti M, Puppo F, et al. Prednisone increases apoptosis in in vitro activated human peripheral blood T lymphocytes. Clin Exp Immunol 1996;103:482-90.

7 Northrop JP, Crabtree GR, Mattila PS. Negative regulation of interleukin 2 transcription by the glucocorticoid receptor. F Exp Med 1992;175:1235-45.

8 Guizani L, Perrin WM, Breard J, et al. Mechanisms in interleukin-2 protection against glucocorticoid-induced apoptosis: regulation of AP-1 and glucocorticoid receptor 601-9.

9 Schmidt M, Pauels HG, Lugering N, et al. Glucocorticoids induce apoptosis in human monocytes: potential role of induce apoptosis in human monocytes:

10 Jantzen HM, Strahle U, Gloss B, et al. Cooperativity of glucocorticoid response elements located far upstream of the tyrosine aminotransferase gene. Cell 1987;49:29-38

11 Hanson RW, Reshef L. Regulation of phosphoenolpyruvate carboxykinase (GTP) gene expression. Annu Rev Biochem 1997;66:581-611

12 Karin $M$. New twists in gene regulation by glucocorticoid receptor: is DNA binding dispensable? Cell 1998;93:48790.

13 Reichardt HM, Schutz G. Glucocorticoid signalling: multiple variations of a common theme. Mol Cell Endocrinol 1998;146:1-6.

14 Barnes PJ, Karin M. Nuclear factor- $\kappa B$ : a pivotal transcription factor in chronic inflammatory diseases. $N$ Engl $F \mathrm{Med}$ 1997;336:1066-71.

15 Hollenberg SM, Weinberger C, Ong ES, et al. Primary structure and expression of a functional human glucocorti-
coid receptor cDNA. Nature 1985;318:635-41.

16 Giguere V, Hollenberg SM, Rosenfeld MG, et al. Functional domains of the human glucocorticoid receptor. Cell 1986;46:645-52.

17 Hollenberg SM, Evans RM. Multiple and cooperative transactivation domains of the human glucocorticoid receptor. Cell 1988;55:899-906.

18 Dahlman-Wright $\mathrm{K}$, Baumann $\mathrm{H}$, McEwan IJ, et al. Structural characterization of a minimal functional transactivation domain from the human glucocorticoid receptor. Proc Natl Acad Sci USA 1995;92:1699-703.

19 Beato M, Truss M, Chavez S. Control of transcription by steroid hormones. Ann NY Acad Sci 1996;784:93-123.

20 Bamberger CM, Bamberger AM, de Castro M, et al. Glucocorticoid receptor beta, a potential endogenous inhibitor of glucocorticoid action in humans. F Clin Invest 1995;95: glucocortico

21 Oakley RH, Jewell CM, Yudt MR, et al. The dominant negative activity of the human glucocorticoid receptor beta isoform. Specificity and mechanisms of action. $\mathcal{F}$ Biol Chem 1999;274:27857-66.

22 Beato M. Gene regulation by steroid hormones. Cell 1989;56:335-44.

23 Strahle U, Klock G, Schutz G. A DNA sequence of 15 base pairs is sufficient to mediate both glucocorticoid and progesterone induction of gene expression. Proc Natl Acad Sci USA 1987;84:7871-5.

24 Karin $\mathrm{M}$, Haslinger A, Holtgreve $\mathrm{H}$, et al. Characterization of DNA sequences through which cadmium and glucocorticoid hormones induce human metallothionein-IIA gene. Nature 1984;308:513-9.

25 Webster MK, Goya L, Ge Y, et al. Characterization of $s g k$, a novel member of the serine/threonine protein kinase gene
family which is transcriptionally induced by glucocorticoids and serum. F Biol Chem 1993;13:2031-40.
26 Renkawitz R, Schutz G, von-der-Ahe D, et al. Sequences in the promoter region of the chicken lysozyme gene required for steroid regulation and receptor binding. Cell 1984;37: 503-10.

27 Stromstedt PE, Poellinger L, Gustafsson JA, et al. The glucocorticoid receptor binds to a sequence overlapping the TATA box of the human osteocalcin promoter: a potential mechanism for negative regulation. $\mathcal{F}$ Biol Chem 1991;11: 3379-83.

28 Dahlman WK, Wright A, Gustafsson JA, et al. Interaction of the glucocorticoid receptor DNA-binding domain with DNA as a dimer is mediated by a short segment of five amino acids. F Biol Chem 1991;266:3107-12.

29 Flower RJ, Rothwell NJ. Lipocortin-1: cellular mechanisms and clinical relevance. Trends Pharmacol Sci 1994;15:71-6.

30 Yao XL, Cowan MJ, Gladwin MT, et al. Dexamethasone alters arachidonate release from human epithelial cells by induction of p11 protein synthesis and inhibition of phospholipase A2 activity. F Biol Chem 1999;274:17202-8.

31 Collins S, Caron MG, Lefkowitz RJ. Beta-adrenergic receptors in hamster smooth muscle cells are transcriptionally regulated by glucocorticoids. F Biol Chem 1988;263:906770 .

32 Mak JC, Nishikawa M, Barnes PJ. Glucocorticosteroids increase beta 2 -adrenergic receptor transcription in human ung. Am f Physiol 1995;268:L41-6.

33 Abbinante NJ, Simpson LG, Leikauf GD. Corticosteroids increase secretory leukocyte protease inhibitor transcript evels in airway epithelial cells. Am f Physiol 1995;268: L601-6.

34 Colotta F, Re F, Muzio M, et al. Interleukin-1 type II receptor: a decoy target for IL-1 that is regulated by IL-4. Science 1993;261:472-5.

35 Taylor IK, Shaw RJ. The mechanism of action of corticosteroids in asthma. Respir Med 1993;87:261-77.

36 Cato AC, Wade E. Molecular mechanisms of antiinflammatory action of glucocorticoids. Bioessays 1996;18: $371-8$

37 Charron J, Drouin J. Glucocorticoid inhibition of transcription from episomal proopiomelanocortin gene promoter. Proc Natl Acad Sci USA 1986;83:8903-7.

38 Drouin J, Sun YL, Chamberland M, et al. Novel glucocorticoid receptor complex with DNA element of the hormonerepressed POMC gene. EMBO F 1993;12:145-56.

39 Riegel AT, Lu Y, Remenick J, et al. Proopiomelanocortin gene promoter elements required for constitutive and glucocorticoid-repressed transcription. Mol Endocrinol 1991;5:1973-82.

40 Murphy EP, Conneely OM. Neuroendocrine regulation of the hypothalamic pituitary adrenal axis by the nurr 1/nur77 subfamily of nuclear receptors. Mol Endocrinol 1997;11:3947

41 Philips A, Maira M, Mullick A, et al. Antagonism between Nur77 and glucocorticoid receptor for control of transcription. F Biol Chem 1997;17:5952-9.

42 Akerblom IE, Slater EP, Beato M, et al. Negative regulation by glucocorticoids through interference with a cAMP responsive enhancer. Science 1988;241:350-3.

43 Meyer T, Gustafsson JA, Carlstedt DJ. Glucocorticoiddependent transcriptional repression of the osteocalcin gependent transcriptional repression of the osteocalcin Biol $1997 ; \mathbf{1 6}: 919-27$.

44 Newton R, Barnes PJ, Adcock IM. Transcription factors. In: Barnes PJ, Rodger IW, Thomson NC, eds. Asthma: Basic mechanisms and clinical management. London: Academic Press, 1998: 459-474.

45 Sakai DD, Helms S, Carlstedt DJ, et al. Hormone-mediated repression: a negative glucocorticoid response element from the bovine prolactin gene. Genes Dev 1988;2:114454.

46 Schule R, Rangarajan P, Kliewer S, et al. Functional antagonism between oncoprotein c-Jun and the glucocorticoid receptor. Cell 1990;62:1217-26.

47 Jonat C, Rahmsdorf HJ, Park KK, et al. Antitumor promotion and antiinflammation: down-modulation of AP-1 (Fos/Jun) activity by glucocorticoid hormone. Cell 1990;62: $1189-204$.

48 Yang Yen HF, Chambard JC, Sun YL, et al. Transcriptional interference between c-Jun and the glucocorticoid receptor: mutual inhibition of DNA binding due to direct protein-protein interaction. Cell 1990;62:1205-15.

49 Konig $\mathrm{H}$, Ponta $\mathrm{H}$, Rahmsdorf $\mathrm{HJ}$, et al. Interference between pathway-specific transcription factors: glucocorticoids antagonize phorbol ester-induced AP-1 activity without altering AP-1 site occupation in vivo. EMBO $f$ 1992;11:2241-6.

50 Ray A, Prefontaine KE. Physical association and functional antagonism between the $\mathrm{p} 65$ subunit of transcription factor NF-kappa B and the glucocorticoid receptor. Proc Natl Acad Sci USA 1994;91:752-6.

51 Scheinman RI, Gualberto A, Jewell CM, et al. Characterization of mechanisms involved in transrepression of NFkappa $\mathrm{B}$ by activated glucocorticoid receptors. $7 \mathrm{Biol}$ Chem 1995;15:943-53.

52 Mukaida N, Morita M, Ishikawa Y, et al. Novel mechanism of glucocorticoid-mediated gene repression. Nuclear factor-kappa B is target for glucocorticoid-mediated interleukin 8 gene repression. F Biol Chem 1994;269:13289-95.

53 Scheinman RI, Cogswell PC, Lofquist AK, et al. Role of transcriptional activation of I kappa B alpha in mediation of immunosuppression by glucocorticoids. Science 1995;270: 283-6. 
54 Auphan N, DiDonato JA, Rosette C, et al. Immunosuppression by glucocorticoids: inhibition of NF-kappa B activity through ind

55 Newton R, Hart LA, Stevens DA, et al. Effect of dexamethasone on interleukin-1beta (IL-1beta) induced nuclear factor-kappaB (NF-kappaB) and kappaB-dependent transcription in epithelial cells. Eur F Biochem 1998;254:81-9.

56 Le Bail O, Schmidt Ullrich R, Israel A. Promoter analysis of the gene encoding the I kappa B-alpha/MAD3 inhibitor of
NF-kappa B: positive regulation by members of the rel/NF-kappa B family. EMBO f 1993;12:5043-9.

57 Vanden Berghe W, Francesconi E, De Bosscher K, et al. Dissociated glucocorticoids with anti-inflammatory potential repress interleukin- 6 gene expression by a nuclear factorkappaB-dependent mechanism. Mol Pharmacol 1999;56: 797-806.

58 Brostian C, Anrather J, Csizmadia V, et al. Glucocorticoids inhibit E-selectin expression by targeting NF-kappaB and inhibit E-selectin expression by targeting NF-

59 Brostjan C, Anrather J, Csizmadia V, et al. Glucocorticoidmediated repression of NFkappaB activity in endothelia cells does not involve induction of I kappa B alpha synthesis. F Biol Chem 1996;271:19612-6.

60 Ray KP, Farrow S, Daly M, et al. Induction of the E-selectin promoter by interleukin 1 and tumour necrosis factor alpha, and inhibition by glucocorticoids. Biochem $\mathcal{F}$ 1997;328:707-15.

61 Ohtsuka T, Kubota A, Hirano T, et al. Glucocorticoidmediated gene suppression of rat cytokine-induced neutrophil chemoattractant CINC/gro, a member of the interleukin-8 family, through impairment of NF-kappa B activation. F Biol Chem 1996;271:1651-9.

62 Heck S, Bender K, Kullman M, et al. IkB $\alpha$-independent downregulation of NF-kB activity by glucocorticoid receptownregulation of NF-kB activity

63 De-Bosscher K, Schmitz ML, Vanden-Berghe W, et al. Glucocorticoid-mediated repression of nuclear factorkappaB-dependent transcription involves direct interference with transactivation. Proc Natl Acad Sci USA 1997;94 13504-9.

64 Heck S, Kullmann M, Gast A, et al. A distinct modulating domain in glucocorticoid receptor monomers in the repression of activity of the transcription factor AP-1. EMBO f 1994;13:4087-95.

65 Kamei Y, Xu L, Heinzel T, et al. A CBP integrator complex mediates transcriptional activation and AP-1 inhibition by nuclear receptors. Cell 1996;85:403-14.

66 Sheppard KA, Phelps KM, Williams AJ, et al. Nuclear integration of glucocorticoid receptor and nuclear factorkappaB signaling by CREB-binding protein and steroid receptor coactivator-1. F Biol Chem 1998;273:29291-4.

67 Kwok RP, Lundblad JR, Chrivia JC, et al. Nuclear protein CBP is a coactivator for the transcription factor CREB. CBP is a coactivator fo

68 Swope DL, Mueller CL, Chrivia JC. CREB-binding protein activates transcription through multiple domains. F Biol Chem 1996;271:28138-45.

69 Chakravarti D, LaMorte VJ, Nelson MC, et al. Role of CBP/P300 in nuclear receptor signalling. Nature 1996;383 99-103.

70 Gerritsen ME, Williams AJ, Neish AS, et al. CREB-binding protein/p300 are transcriptional coactiva

71 Shikama N, Lyon J, La Thange NB. The p300/CBP family: Integrating signals with transcription factors and chromaIntegrating signals with transcription
tin. Trends Cell Biol 1997;7:230-6.

72 Bannister AJ, Kouzarides T. The CBP co-activator is a histone acetyltransferase. Nature 1996;384:641-3.

73 Ogryzko VV, Schiltz RL, Russanova V, et al. The transcriptional coactivators p300 and CBP are histone acetyltransferases. Cell 1996;87:953-9.

74 Yang XJ, Ogryzko VV, Nishikawa J, et al. A p300/CBPassociated factor that competes with the adenovira oncoprotein E1A. Nature 1996;382:319-24.

75 Chen H, Lin RJ, Schiltz RL, et al. Nuclear receptor coactivator ACTR is a novel histone acetyltransferase and form a multimeric activation complex with $\mathrm{P} / \mathrm{CAF}$ and $\mathrm{CBP} /$ p300. Cell 1997;90:569-80.

76 Struhl K. Histone acetylation and transcriptional regulatory mechanisms. Genes Dev 1998;12:599-606.

77 Tsai CC, Kao HY, Yao TP, et al. SMRTER, a Drosophila nuclear receptor coregulator, reveals that EcR-mediated repression is critical for development. Mol Cell 1999;4:17586.

78 Liden J, Delaunay F, Rafter I, et al. A new function for the C-terminal zinc finger of the glucocorticoid receptor. Repression of RelA transactivation. F Biol Chem 1997;272: 21467-72

79 Vayssiere BM, Dupont S, Choquart A, et al. Synthetic glucocorticoids that dissociate transactivation and AP- 1 transrepression exhibit antiinflammatory activity in vivo. Mol Endocrinol 1997;11:1245-55.

80 Meyer T, Carlstedt DJ, Starr DB. A weak TATA box is a prerequisite for glucocorticoid-dependent repression of the osteocalcin gene. F Biol Chem 1997;272:30709-14

81 Hauschka PV, Lian JB, Cole DE, et al. Osteocalcin and matrix Gla protein: vitamin K-dependent proteins in bone. Physiol Rev 1989;69:990-1047.

82 Belvisi MG, Wicks S, Battram C, et al. Does the synthetic glucocorticoid, RU 24858, which dissociates transactivation and transrepression in vitro possess anti-inflammatory properties without steroid adverse side effects in vivo? $A m$ F Respir Crit Care Med 1999;153:A108.
83 Cole TJ, Blendy JA, Monaghan AP, et al. Targeted disruption of the glucocorticoid receptor gene blocks
adrenergic chromaffin cell development and severely adrenergic chromaffin cell development and severc
retards lung maturation. Genes Dev 1995;9:1608-21.

84 Kretz O, Reichardt HM, Schutz G, et al. Corticotropinreleasing hormone expression is the major target for glucocorticoid feedback-control at the hypothalamic level. Brain Res 1999;818:488-91.

85 Reichardt HM, Kaestner KH, Tuckermann J, et al. DNA binding of the glucocorticoid receptor is not essential for survival. Cell 1998;93:531-41.

86 Jacobson A, Peltz SW. Interrelationships of the pathways of mRNA decay and translation in eukaryotic cells. Anпи Rev Biochem 1996;65:693-739.

87 Kleijn M, Scheper GC, Voorma HO, et al. Regulation of translation initiation factors by signal transduction. Eur $\mathcal{F}$ Biochem 1998:253:531-44.

88 Rhoads RE. Signal transduction pathways that regulate eukaryotic protein synthesis. F Biol Chem 1999;274:3033740.

89 Shaw G, Kamen R. A conserved AU sequence from the 3' untranslated region of GM- CSF mRNA mediates selective mRNA degradation. Cell 1986;46:659-67.

90 Huarte J, Stutz A, O'Connell ML, et al. Transient translational silencing by reversible mRNA deadenylation. Cell 1992;69:1021-30.

91 Kruys V, Marinx O, Shaw G, et al. Translational blockade imposed by cytokine-derived UA-rich sequences. Science 1989;245:852-5.

92 Rajagopalan LE, Malter JS. Modulation of granulocytemacrophage colony-stimulating factor mRNA stability in vitro by the adenosine-uridine binding factor. $f$ Biol Chem 1994;269:23882-8.

93 Rajagopalan LE, Burkholder JK, Turner J, et al. Granulocyte-macrophage colony-stimulating factor mRNA stabilization enhances transgenic expression in normal cells and tissues. Blood 1995;86:2551-8.

94 Caput D, Beutler B, Hartog K, et al. Identification of a common nucleotide sequence in the 3 ' untranslated region of mRNA molecules specifying inflammatory mediators. Proc Natl Acad Sci USA 1986;83:1670-4.

95 Yang L, Yang YC. Regulation of interleukin (IL)-11 gene expression in IL-1 induced primate bone marrow stromal cells. F Biol Chem 1994;269:32732-9.

96 Kern JA, Warnock LJ, McCafferty JD. The 3' untranslated region of IL-1 beta regulates protein production. F Immunol 1997; 158:1187-93.

97 Henics T, Sanfridson A, Hamilton BJ, et al. Enhanced stability of interleukin-2 mRNA in MLA 144 cells. Possible role of cytoplasmic AU-rich sequence-binding proteins. $\mathcal{F}$ Biol Chem 1994;269:5377-83.

98 Chen CY, Del Gatto Konczak F, Wu Z, et al. Stabilization of interleukin-2 mRNA by the c-Jun NH2-terminal kinase interleukin-2 mRNA by the c-Jun
pathway. . Science 1998;280:1945-9.

pathway. . Science $1998 ; 280: 1945-9$.
99 Winzen R, Kracht M, Ritter B, et al. The p38 MAP kinase pathway signals for cytokine-induced mRNA stabilization via MAP kinase-activated protein kinase 2 and an AU-rich region-targeted mechanism. EMBO f 1999;18:4969-80.

100 Ristimaki A, Garfinkel S, Wessendorf J, et al. Induction of cyclooxygenase-2 by interleukin-1 alpha. Evidence for post-transcriptional regulation. F Biol Chem 1994;269: $11769-75$.

101 Newton R, Seybold S, Liu SF, et al. Alternate COX-2 transcripts are differentially regulated: implications for posttranscriptional control. Biochem Biophys Res Commun 1997;234:85-9.

102 Barrios RM, Tiraloche G, Chadee K. Lipopolysaccharide modulates cyclooxygenase- 2 transcriptionally and postranscriptionally in human macrophages independently from endogenous IL-1 beta and TNF-alpha. F Immunol 1999;163:963-9.

103 Mitchell JA, Belvisi MG, Akarasereenont P, et al. Induction of cyclo-oxygenase- 2 by cytokines in human pulmonary epithelial cells: regulation by dexamethasone. BrF Pharmacol 1994;113:1008-14

104 Newton R, Kuitert LM, Slater DM, et al. Cytokine induction of cytosolic phospholipase $\mathrm{A}_{2}$ and cyclooxygenase-2 mRNA is suppressed by glucocorticoids in human epithelial cells. Life Sci 1997;60:67-78.

105 Newton R, Kuitert LM, Bergmann M, et al. Evidence for involvement of NF- $\mathrm{NB}$ in the transcriptional control of COX-2 gene expression by IL-1 $\beta$. Biochem Biophys Res Commun 1997;237:28-32.

106 Newton R, Seybold J, Kuitert LME, et al. Repression of cyclooxygenase- 2 and prostaglandin $\mathrm{E}_{2}$ release by dexamethasone occurs by transcriptional and post-transcriptional mechanisms involving loss of polyadenylated mRNA. F Biol Chem 1998;273:32312-21.

107 Krane IM, Spindel ER, Chin WW. Thyroid hormone decreases the stability and the poly(A) tract length of rat thyrotropin beta-subunit messenger RNA. Mol Endocrinol 1991;5:469-75.

108 Crawford EK, Ensor JE, Kalvakolanu I, et al. The role of 3' poly(A) tail metabolism in tumor necrosis factor-alpha regulation. F Biol Chem 1997;272:21120-7.

109 Ristimaki A, Narko K, Hla T. Down-regulation of cytokine-induced cyclo-oxygenase- 2 transcript isoforms by dexamethasone: evidence for post-transcriptional regulation. Biochem f 1996;318:325-31.

110 Lee SW, Tsou AP, Chan H, et al. Glucocorticoids selectively inhibit the transcription of the interleukin 1 beta gene and decrease the stability of interleukin 1 beta 
111 Kern JA, Lamb RJ, Reed JC, et al. Dexamethasone inhibition of interleukin 1 beta production by human monocytes.
Posttranscriptional mechanisms. F Clin Invest 1988;81: 237-44.

112 Tobler A, Meier R, Seitz M, et al. Glucocorticoids downregulate gene expression of GM-CSF, NAP-1/IL-8, and IL-6, but not of M-CSF in human fibroblasts. Blood 1992;79:45-51

113 Knudsen PJ, Dinarello CA, Strom TB. Glucocorticoids inhibit transcriptional and post-transcriptional expression of interleukin 1 in U937 cells. F Immunol 1987;139:412934.

114 Peppel K, Vinci JM, Baglioni C. The AU-rich sequences in the 3 ' untranslated region mediate the increased turnover of interferon mRNA induced by glucocorticoids. 7 Exp Med 1991;173:349-55.

115 Walker G, Pfeilschifter J, Kunz D. Mechanisms of suppression of inducible nitric-oxide synthase (iNOS) expression in interferon (IFN)-gamma-stimulated RAW 264.7 cells by in interferon (IFN)-gamma-stimulated RAW 264.7 cells by radation of iNOS protein by calpain as a key step in postradation of iNOS protein by calpain as a key step in posttrans 87.

116 Swantek JL, Cobb MH, Geppert TD. Jun N-terminal kinase/stress-activated protein kinase (JNK/SAPK) is required for lipopolysaccharide stimulation of tumor necrosis factor alpha (TNF-alpha) translation: glucocorticoids inhibit TNF-alpha translation by blocking JNK SAPK. F Biol Chem 1997;17:6274-82.

117 Han J, Brown T, Beutler B. Endotoxin-responsive sequences control cachectin/tumor necrosis factor biosynthesis at the translational level. F Exp Med 1990;171:465-75; 971-2 (erratum)

118 Han J, Huez G, Beutler B. Interactive effects of the tumor necrosis factor promoter and $3^{\prime}$ untranslated regions. $\mathcal{F}$ Immunol 1991;146:1843-8.

119 Gueydan C, Droogmans L, Chalon P, et al. Identification of TIAR as a protein binding to the translational regulatory AU-rich element of tumor necrosis factor alpha mRNA. $\mathcal{F}$ Biol Chem 1999;274:2322-6.

120 Huang S, Hershey JW. Translational initiation factor expression and ribosomal protein gene expression are repressed coordinately but by different mechanisms in murine lymphosarcoma cells treated with glucocorticoids. f Biol Chem 1989;9:3679-84.

121 Newton R, Staples KJ, Nasuhara Y, et al. Inhibition of GM-CSF synthesis by glucocorticoids does not involve down-regulation of promoter activity in primary human T-cells. Am f Respir Crit Care Med 1999;159:A754

122 Poon M, Liu B, Taubman MB. Identification of a novel dexamethasone-sensitive RNA-destabilizing region on rat monocyte chemoattractant protein $1 \mathrm{mRNA} \mathcal{F}$ Biol Chem 1999;19:6471-8.

123 Cidlowski JA, King KL, Evans SR, et al. The biochemistry and molecular biology of glucocorticoid-induced apoptosis in the

124 Nieto MA, Gonzalez A, Gambon F, et al. Apoptosis in human thymocytes after treatment with glucocorticoids. Clin Exp Immunol 1992;88:341-4.

125 Wyllie AH, Morris RG, Smith AL, et al. Chromatin cleavage in apoptosis: association with condensed chromatin morphology and dependence on macromolecular synthesis. $\mathcal{F}$ Pathol 1984;142:67-77.

126 Ramdas J, Hasday JD. Glucocorticoid-induced apoptosis and regulation of NF-kappaB activity in human leukemic T cells. Endocrinology 1998;139:3813-21.

127 Reisman D, Thompson EA. Glucocorticoid regulation of cyclin D3 gene transcription and mRNA stability in ymphoid cells. Mol Endocrinol 1995;9:1500-9.

128 Diamond MI, Miner JN, Yoshinaga SK, et al. Transcription factor interactions: selectors of positive or negative tion factor interactions: selectors of positive or negative regulation fir

129 Pearce D, Yamamoto KR. Mineralocorticoid and glucocorticoid receptor activities distinguished by nonreceptor factors at a composite response element. Science 1993;259: 1161-5.

130 Pearce D, Matsui W, Miner JN, et al. Glucocorticoid receptor transcriptional activity determined by spacing of receptor and nonreceptor DNA sites. F Biol Chem 1998;273:30081-5.

131 Schule R, Muller M, Otsuka Murakami H, et al. Cooperativity of the glucocorticoid receptor and the CACCC-box binding factor. Nature 1988;332:87-90.

132 Strahle U, Schmid W, Schutz G. Synergistic action of the glucocorticoid receptor with transcription factors. $E M B O \mathcal{F}$ 1988;7:3389-95.

133 Schule R, Muller M, Kaltschmidt C, et al. Many transcription factors interact synergistically with steroid receptors. Science 1988;242:1418-20.

134 Gotoh T, Chowdhury S, Takiguchi M, et al. The glucocorticoid-responsive gene cascade. Activation of the rat arginase gene through induction of C/EBPbeta. F Biol Chem 1997;272:3694-8.

135 Imai E, Miner JN, Mitchell JA, et al. Glucocorticoid receptor-cAMP response element-binding protein interaction and the response of the phosphoenolpyruvate carboxykinase gene to glucocorticoids. F Biol Chem 1993;268: 5353-6.

136 Kordula T, Travis J. The role of Stat and C/EBP transcription factors in the synergistic activation of rat serine protease inhibitor-3 gene by interleukin- 6 and dexamethasone. Biochem f 1996;313:1019-27.

137 Stocklin E, Wissler M, Gouilleux F, et al. Functional interactions between Stat5 and the glucocorticoid receptor. Nature 1997;383:726-8.

138 Cella N, Groner B, Hynes NE. Characterization of Stat5a and Stat5b homodimers and heterodimers and their association with the glucocortiocoid receptor in mammary cells. F Biol Chem 1998;18:1783-92.

139 Klauck TM, Xu X, Mousseau B, et al. Cloning and characterization of a glucocorticoid-induced diacylglycerol kinase. F Biol Chem 1996;271:19781-8.

140 Kemppainen RJ, Behrend EN. Dexamethasone rapidly induces a novel ras superfamily member-related gene in AtT-20 cells. 7 Biol Chem 1998;273:3129-31.

141 Dunham I, Shimizu N, Roe BA, et al. The DNA sequence of human chromosome 22. Nature 1999;402:489-95.

142 Cheung VG, Morley M, Aguilar F, et al. Making and reading microarrays. Nature Genetics 1999;21:15-9. 